\title{
¿Actores de reparto? Los obreros agrícolas pampeanos en los inicios de la etapa agroexportadora: afluentes, tareas, organización y conflictos (1880-1904)
}

\author{
Pablo Volkind \\ Universidad de Buenos Aires (FFYL - FCE) - Centro Interdisciplinario de Estudios Agrarios \\ pvolkind@gmail.com
}

Title: Supporting actors? The Pampean agricultural workers at the beginning of the agro-export period: tributaries, tasks, organization and conflicts

Resumen: Este artículo indaga sobre los orígenes del proletariado agrícola bonaerense durante las últimas décadas del siglo XIX. En este período se evidencia una notable expansión agrícola que requirió del concurso de miles de trabajadores asalariados que trabajaban entre noviembre y mayo para cosechar el trigo y el maíz. La atención se concentra sobre aquellos que desarrollaban sus tareas dentro de las explotaciones: ¿de dónde provenían?, ¿cuáles eran sus labores?, ¿en qué condiciones trabajaban?, ¿cuáles fueron los primeros conflictos? Estos interrogantes estructuran el artículo y permiten identificar la centralidad de esta fracción de la clase obrera argentina durante los inicios de la etapa agroexportadora.

Palabras clave: trabajadores agrícolas - condiciones laborales - etapa agroexportadora - Buenos Aires

Abstract: This article explores the origins of the agricultural proletariat in Buenos Aires during the last decades of the 19th century. In this period there is evidence of a remarkable agricultural expansion that required the assistance of thousands of salaried workers who worked between November and May to harvest wheat and corn. The attention is concentrated on those who developed their tasks within the farms: where did they come from? What were their jobs? In what conditions did they work? and what were the first conflicts? These are the questions that structure this writing and allow us to identify the centrality of this fraction of the working class during the beginning of the agro-export stage. Key words: agricultural workers - labor conditions - agro-exporting period Buenos Aires

Recepción: 12 de enero de 2019. Aceptación: 1 de febrero de 2019.

(Archivos, año VII, no ${ }^{\circ}$, marzo de 2019, pp. 75-96) 


\section{Introducción}

Los estudios sobre la historia del movimiento obrero argentino se concentran, en su mayoria, en el análisis de los procesos y acontecimientos que se desarrollaron en el ámbito urbano. Esto resulta comprensible dado que para 1914 la población registrada en las ciudades ya superaba a la radicada en el campo, proceso que se aceleraría con el crecimiento del comercio, los servicios y la industria en el país. Sin embargo, entre fines del siglo XIX e inicios del XX, los trabajadores rurales tuvieron un papel fundamental -tanto en términos cuantitativos como cualitativos- no sólo en la producción de mercancías sino también en la conflictividad social.

En este trabajo, indagamos sobre los orígenes del proletariado agrícola pampeano durante las últimas décadas del siglo XIX, momento en que la Argentina se transformó en un país capitalista y dependiente con eje en la producción agropecuaria para la exportación. El recorte cronológico del tema se fundamenta en que hacia 1880 se inicia el proceso de consolidación de esta relevante fracción de la clase obrera argentina, etapa que se extiende hasta los inicios del siglo XX cuando dicha fracción protagoniza sus primeros conflictos colectivos. A lo largo de estos 24 años pueden identificarse múltiples elementos comunes que le otorgan una fisonomía particular al período y que se evidencian tanto en el plano objetivo como subjetivo. A su vez, para poder captar los diversos factores que concurrieron e interactuaron en los procesos de producción y a fin de iluminar el fenómeno general, en el trabajo se concentra la atención en la provincia de Buenos Aires, ya que resulta altamente representativa de lo sucedido en la región pampeana.

Para abordar esta problemática se analizaron una variada gama de fuentes cuantitativas y cualitativas entre las que se destacan los boletines de población del partido de Pergamino del Segundo Censo de la República Argentina, efectuado en 1895, y diversas publicaciones periódicas como La Protesta, La Vanguardia, La Agricultura, La Nación y La Prensa. También se consultaron boletines, anuarios, censos e informes elaborados por las distintas dependencias del Ministerio de Agricultura de la Nación y del Ministerio de Obras Públicas de la Provincia de Buenos Aires.

El cultivo de la tierra requería la puesta en práctica de un conjunto de labores, diversas temporalidades y disímiles grados de calificación. En el presente escrito se focaliza la mirada sobre aquellos que desarrollaban sus tareas dentro de las explotaciones, los "estrictamente rurales". ¿Cuántos eran? ¿De dónde provenían? ¿Cuáles eran las labores que debían llevar adelante? ¿En qué condiciones desempeñaron sus tareas? ¿Cuáles fueron los primeros conflictos que protagonizaron? Interrogan- 
tes que estructuran este escrito y permiten identificar la centralidad de estos trabajadores durante los inicios de la etapa agroexportadora.

$\mathrm{Al}$ respecto se advierten interpretaciones contrapuestas. Desde una visión apologética de aquel período, se enfatizan las múltiples oportunidades que tenian los jornaleros rurales para transitar un camino de ascenso social (Míguez, 1993), lo atractivo que resultaban los salarios ofrecidos en las tareas agrarias (Beccaria, 2006) y el armónico funcionamiento del mercado de trabajo que tendia a equilibrarse sobre la base de la elasticidad de ese peculiar factor de producción (Cortés Conde, 1979; Díaz Alejandro, 1975). Estas lecturas presuponen la ahistoricidad de las leyes económicas y las formas de producción, eternizando las relaciones propias del capitalismo. Más aún, desestiman los debates en torno a las formas particulares que tuvo el desarrollo de dicho modo de producción en Argentina.

Otro grupo de autores, desde perspectivas heterogéneas, aportaron posiciones más críticas sobre la situación de los obreros agrícolas, sus condiciones laborales y los recurrentes y prolongados períodos de desocupación a los que estaban sometidos la mayoria de los trabajadores rurales (Ansaldi, 1993; Ascolani, 1993, 1997; Sartelli, 2005; Pianetto, 1984; Blanc Bloquel, Bonaudo, Sonzogni y Yensina, 1987; Adelman, 1989). Más atentas a la historicidad de los procesos, algunas investigaciones proponen que en Argentina el régimen de producción capitalista pasó a predominar entre 1850 y 1880 (Sábato y Romero, 1992; Sartelli, 1997).

Entre ambas corrientes se pueden identificar, sin embargo, algunas coincidencias: la jerarquización del carácter elevado de los jornales rurales así como el papel protagónico que le otorgan a los inmigrantes en la formación del proletariado agrícola pampeano (Sartelli, 1993; Palacio, 2004; Ascolani, 1998; Sansoni, 1990).

La pertinencia de estudiar hoy a los obreros agrícolas de aquella etapa agroexportadora se deriva de la relevancia que aún tiene en nuestro país esta rama productiva. Esto se expresa con mucha nitidez en que, en las últimas décadas, aparece, tomada en su conjunto para las diversas economías regionales y en diversas estadísticas, como la actividad que cuenta con el mayor número de asalariados. Al mismo tiempo, por el grado de precarización, estacionalidad y trabajo informal imperante, es notoria la dificultad de cuantificación general, que obliga a los estudios de caso. En relación a este presente complejo, vinculado a la importancia de la mano de obra rural en una de las principales producciones del país, es importante rastrear el origen de la formación y el desarrollo de este actor social fundamental.

Determinar las diversas formas que fue adoptando la expansión de la mano de obra asalariada (inmigrante y criolla) en la agricultura permitirá 
reconstruir históricamente el pasaje del nivel económico de existencia de los trabajadores asalariados a su "formación social" como actores concretos en el plano gremial, político y cultural, en sus relaciones y conflictividad con los otros actores sociales agrarios y con la sociedad urbana de la que muchos formaban parte.

\section{Condiciones para el predominio del trabajo rural asalariado}

Durante el período que culmina en 1880 (cuyo inicio lo ubicamos hacia mediados del siglo XIX) se crearon las precondiciones básicas para el desarrollo y consolidación del capitalismo en la región pampeana, las cuales se manifestaron tanto en el plano material como en el político-jurídico.

En las décadas de 1860 y 1870 la fuerza de trabajo efectivamente asalariada comenzó a adquirir una mayor relevancia, especialmente en Buenos Aires, asociada principalmente a actividades comerciales y artesanales urbanas, así como a la construcción del ferrocarril. Si bien todavía este medio de transporte sólo conectaba los partidos próximos a la ciudad de Buenos Aires, tuvo un papel muy importante en dos sentidos: fue generando un nuevo estímulo a la producción en distritos más alejados y, al mismo tiempo, afianzó un nuevo tipo de vínculo laboral estable y mediado por el salario (Sabato y Romero, 1992).

También en los ámbitos rurales bonaerenses, en relación con la expansión sin precedentes del ganado ovino, se fueron extendiendo/ ampliando dichas relaciones salariales. Parte del salario que recibian los peones temporarios se establecía en comida, vivienda y "vicios" (antiguo nombre dado a productos como yerba, tabaco y alcohol) y sólo una pequeña proporción en moneda (Sabato, 1989: 36). En muchos casos la parte monetaria de la paga se efectuaba en vales que debian ser canjeados en la propia proveeduría de la estancia o de algún socio del estanciero; es decir que un porcentaje significativo del ingreso de muchos jornaleros continuaba siendo un estipendio de apariencia salarial antes que un auténtico salario moderno, dado que principalmente garantizaba la reproducción de su fuerza de trabajo a través de actividades de autosubsistencia (Azcuy, 2011: 16-42).

Este proceso de conformación de un mercado de fuerza de trabajo a escala social recorrió un sinuoso camino en el ámbito rural, dado que convivian alli elementos contradictorios propios de una etapa de transición y acumulación originaria. Por un lado, crecía la demanda de jornaleros y cada vez resultaba más dificil para campesinos y artesanos acceder a los medios de producción o conservarlos. Por el otro, se promulgaba el Código Rural de la provincia de Buenos Aires (1865), que daba muestras claras acerca de la dificultad que todavía existía para 
reclutar trabajadores en las zonas rurales y el peso que mantenían diversos mecanismos de presión extraeconómica (en este caso legal) para lograr aquel fin. Aún eran etapas de la historia argentina en donde la frontera hacia el sur no se había consolidado y era posible sobrevivir, para un sector de la población, eludiendo la telaraña de las relaciones salariales. Justamente, dicho Código tenía por objeto el control y disciplinamiento de la fuerza de trabajo y tipificó los delitos rurales con especial énfasis en el robo de ganado o la caza que posibilitaban vivir "sin trabajar para otro". Además, impuso la obligatoriedad de portar un documento de trabajo para poder transitar por la campaña (disposición que fue eliminada en 1873), y simultáneamente estipuló salarios y condiciones de trabajo para los peones (Martinez Dougnac, 2010: 37-39).

Los jornaleros quedaron excluidos de la reglamentación y no gozaron de ningún tipo de amparo legal. Por el contrario, si bien se fijó el descanso dominical, quedaron exceptuados los periodos de cosecha y esquila que debían garantizarse de forma ininterrumpida. De este modo, y a pesar de que el Código Rural perdió vigencia en la década de 1880 , se inauguraba una historia de precariedad y desamparo para los trabajadores rurales más pobres (los transitorios) que se extendería hasta la década de 1940.

Otro de los tópicos característicos de este proceso fue la progresiva consolidación de la moderna propiedad privada de la tierra, la cual se operó, principalmente, a través de la apropiación latifundista del espacio rural que pasó de las comunidades originarias o el fisco a manos particulares. Una de las claras manifestaciones de este derrotero se materializó en el alambrado de los campos que delimitaron con exactitud las dimensiones de las propiedades. Si bien el alambre para cercos había sido introducido ya en 1845 por Newton desde Inglaterra, esta práctica recién se generalizó en Buenos Aires durante la década de 1880 .

De este modo, se fue cerrando el acceso directo a los medios de vida para un porcentaje significativo de la población rural que alternaba el trabajo en la esquila o la cosecha de granos con otras formas de supervivencia como el cultivo de una pequeña parcela, la caza de animales, la apropiación del ganado o alguna "changa" en el pueblo. ${ }^{1}$ La transitoriedad de las labores asalariadas y las formas alternativas de supervivencia tuvieron su correlato en la forma que adoptó el descontento y la conflictividad de este período. Lejos de coagular en una organización colectiva, la elaboración de un pliego de reivindicaciones y la huelga como medida de lucha, se expresó a través de fugas y desplazamientos hacia otras latitudes.

1. Archivo General de la Nación (AGN), Colecciones particulares, Fondo Luis María Doyhenard, Sala VII, legajo 3554 (1882-1902), f. 118. 
Durante estas décadas el crecimiento de la agricultura en Buenos Aires tuvo un papel mucho menos relevante que la ganadería. Hasta los inicios de la década de 1860 casi no se registraban iniciativas concretas para fomentar la colonización en la provincia. A pesar de los avances generados en la primera mitad del siglo XIX, el cultivo de la tierra se circunscribía al área periurbana y a un limitado número de colonias como las de Chivilcoy y Baradero.

Durante esta etapa transicional, los principales cambios en las prácticas agrícolas tuvieron su epicentro en las colonias del Litoral. Entre mediados del siglo XIX y la década de 1880, las provincias de Santa Fe y Entre Ríos fueron escenario de cambios sustanciales en las prácticas que acompañaron la extensión de las superficies cultivadas, el acceso a la propiedad de un número significativo de agricultores $\mathrm{y}$, sobre todo, la organización de nuevos procesos de producción que requerian el uso de máquinas y la creciente demanda de trabajadores asalariados, dado que la dimensión de las parcelas superaba la capacidad de trabajo de la mano de obra familiar (Gallo, 1984). Fue en estos espacios donde se ensayaron y consolidaron las nuevas formas productivas que luego se irradiarian al resto de la región pampeana, particularmente a Buenos Aires.

\section{El proletariado agrícola bonaerense entra en escena}

En la década de 1880 se operaron transformaciones que resultaron en la consolidación de una formación económico-social capitalista y dependiente. En un proceso simultáneo y contradictorio, aumentó la producción y crecieron las ciudades, la inmigración extranjera y la demanda de trabajadores temporarios en las zonas urbanas y rurales.

La expansión de la agricultura y la ganaderia durante estas décadas, y las tareas transitorias asociadas a ambas actividades, fueron un factor fundamental en la estructuración de un mercado rural de fuerza de trabajo asalariado. Aunque persistía en los inicios de la década de 1880 el predominio del ganado lanar, la agricultura se iría abriendo paso estimulada por el incremento de la demanda mundial de granos y las necesidades de refinamiento del ganado. Al respecto, pueden identificarse dos momentos en el desarrollo de la superficie cultivada interrumpidos por la crisis del 90 y sus efectos: el primero se extendió de 1880 a 1889 , mientras que el segundo se inició en 1895 y se prolongó hasta los primeros años del nuevo siglo. Así, en la primera etapa el área implantada con trigo, maíz y lino ascendió de 220.000 a 910.000 hectáreas, mientras que en la segunda pasó de 1.100 .000 hectáreas a más de 2.500.000.

El crecimiento del área sembrada -fundamentalmente la de maízestaba vinculado a la puesta en producción de partidos más alejados 
de la ciudad de Buenos Aires donde se multiplicaban las unidades agrícolas de diversas dimensiones que demandaban fuerza de trabajo extrafamiliar para ejecutar las distintas y sucesivas labores. ${ }^{2}$ Primero estaban aquellas vinculadas a la preparación del suelo, la siembra y el cuidado de los cultivos, y luego se encontraban las que requerian mayor volumen de mano de obra: la cosecha y la trilla de los granos.

Para las tareas iniciales prácticamente no se requerían asalariados. La mayoría de las chacras no tenía más de 200 hectáreas y el grupo familiar podia resolverlas si contaba con dos adultos y un niño mayor de 7 años (Raña, 1904: 120). Las condiciones se modificaban en el turno de la recolección. En ese momento el titular de la explotación necesitaba indiscutiblemente contratar jornaleros. Para segar el trigo o el lino eran necesarios -en promedio- unos 5 a 7 peones, que en 20 dias cosechaban alrededor de 150 hectáreas (Miatello, 1904: 251-254).

Posteriormente, para obtener el grano embolsado, se efectuaba la trilla, que demandaba un mayor número de operarios. Ahí entraban en escena los contratistas que, en aquel periodo, eran mayoritariamente empresarios poseedores de un volumen importante de capital en maquinaria o terratenientes que disponían de las mismas. Para proveer el servicio se desplazaban de chacra en chacra con la trilladora, el motor a vapor y un contingente de 20 a 25 trabajadores que cumplian diversas tareas y poseian distintas calificaciones. El maquinista tenía a su cargo el funcionamiento del equipo y el foguista se encargaba del motor a vapor. También había un engrasador, dos embocadores, dos plancheros y 6 a 8 horquilleros que debian alimentar la trilladora con las gavillas de trigo. El "yuguero" debía retirar la paja de la cola de la máquina, el "rondador" se ocupaba del cuidado de los animales. Completaban la cuadrilla el embolsador, el cosedor, un cocinero y el aguatero (Raña, 1904: 143).

Cuando se terminaba el trabajo de la trilladora en una parcela, los obreros desmontaban todo y lo trasladaban hasta la próxima explotación para reiniciar el proceso. Cada temporada de trilla podía extenderse entre 40 y 60 días y, en algunos casos, alcanzaba los tres meses. Para 1896 se registraron en territorio bonaerense 892 trilladoras mientras que en 1881 ese número apenas ascendía a 66 (Cilley Vernet, 1896: 60). El sustancial incremento de la maquinaria puesta en uso tuvo su correlato en el aumento de la demanda de asalariados.

En el caso de la cosecha del maíz, existía una diferencia importante con respecto a la recolección de granos finos dado que la juntada se realizaba de manera manual, por lo que requería el concurso de una enorme cantidad de trabajadores y trabajadoras de tipo temporario.

2. Según los datos del Segundo Censo de la República Argentina, en 1895 se registraron 36.777 unidades agrícolas en la provincia de Buenos Aires. 
Esta tarea comenzaba en el norte de la provincia de Buenos Aires hacia el mes de marzo y podía extenderse, en algunos casos, hasta junio. En estas labores participaban mujeres, hombres y niños que tomaban parte de esta sacrificada tarea en condiciones inhumanas. ${ }^{3}$

Una vez instalados los juntadores en la parcela, reconocian el lote a cosechar y marcaban el área que le correspondería a cada uno. Luego se distribuía la cantidad de hileras, a las que se denominaban "luchas", que cada trabajador debía recolectar. Esas eran sus "luchas diarias". En general, estos obreros podían completar una hectárea de maíz en 5 o 6 dias aproximadamente (Miatello, 1904: 399-400). Posteriormente a la juntada se efectuaba el desgrane, utilizando, en general, máquinas estáticas impulsadas por motores a vapor, muy similares a las requeridas para la trilla del trigo y el lino.

Así, puede advertirse que los trabajadores asalariados, en su mayoría transitorios, fueron protagonistas destacados en la expansión agrícola de fines del siglo XIX. En la década de 1880 oscilaron en torno a los $20.000 / 30.000$ jornaleros y para los inicios del XX, se calculaban que eran necesarios 70.000 obreros para garantizar las cosechas (Lahitte, 1905: 72).

\section{Todos los caminos conducen a las cosechas}

Estos trabajadores, durante la primera etapa del auge agrícola, provenían fundamentalmente de dos afluentes: la población de las zonas rurales y pueblos de los partidos bonaerenses y de la ciudad de Buenos Aires, a la cual arribaban anualmente miles de europeos. En menor medida -tal como sucedía desde el período colonial- acudian también pobladores de otras provincias.

La mano de obra asalariada que participaba en las cosechas residia, generalmente, en las zonas próximas. Una parte minoritaria estaba compuesta por individuos que habitaban en explotaciones de hasta 10 hectáreas y debían complementar el ingreso de su parcela con la venta de su fuerza de trabajo a efectos de alcanzar la reproducción del grupo familiar. ${ }^{4}$

Otra porción de los trabajadores asalariados estaba constituida por los habitantes de las pequeñas ciudades y pueblos del interior provincial que sobrevivian intercalando el trabajo en la esquila de las ovejas (durante los meses de octubre, noviembre y diciembre) con la posterior cosecha de trigo (diciembre, enero y febrero) y maíz (marzo, abril, mayo) para luego buscar ocupación en diversas "changas", o sobrevivir mediante la

3. La Agricultura, 4 de abril de 1895; La Vanguardia, 10 de septiembre de 1904.

4. La Agricultura, 2 de agosto de 1894. 
caza de animales menores que les permitian resolver su alimentación. En este sentido, el desarrollo del capitalismo los había expropiado de los medios de producción ipero no había estabilizado todavía en las áreas rurales una demanda solvente capaz de determinar -sin perjuicio del ejército de reserva- un proletariado full time!

Al respecto, resulta ilustrativo analizar la composición de la población rural de la provincia. Aunque el panorama ocupacional que brinda el censo resulta insuficiente -porque subregistra el trabajo de mujeres, niños y jóvenes-, habilita una aproximación general a la problemática. En este sentido, podemos advertir que en el distrito bonaerense de Pergamino -el tercero más poblado luego de La Plata y Chivilcoy- el 32,5\% de las personas registradas en 1895 (mayores de 14 años) declaraban desempeñarse como jornaleros/as. De este grupo, el 67\% eran argentinos y en su mayoría habian nacido en la provincia de Buenos Aires. E1 $33 \%$ restante se distribuia de la siguiente manera: $20 \%$ eran italianos, el 6\% eran españoles, el 3\% eran franceses y el 4\% restante de otros países europeos. Además, eran numerosos los grupos familiares que trabajaban en las zonas rurales. En muchos de estos casos, el hombre se desempeñaba como jornalero mientras que la mujer era contratada como costurera, cocinera, lavandera, planchadora e inclusive jornalera. Los hijos e hijas mayores de 12 o 13 años también efectuaban diversas tareas similares a las de sus padres. Esta era la única forma en que el grupo familiar podía conseguir los medios de vida básicos para su subsistencia. El papel de las mujeres resultaba fundamental, y si bien sólo figuran registradas con ocupación remunerada el 31,5\% de las habitantes de Pergamino mayores de 14 años, eran miles las que se desplazaban a los campos durante las cosechas. ${ }^{5}$

En estos años iniciales de la expansión agrícola bonaerense, la proporción de jornaleros nacidos en Argentina era una clara señal de dos fenómenos: por un lado, el proceso de proletarización que se venía desplegando en la población rural local y, en segundo término, las mayores posibilidades que tenían los inmigrantes para instalarse como agricultores junto a la preferencia de otros por permanecer en las zonas urbanas. De este modo, se puede advertir la relevancia de los criollos en la inicial conformación del proletariado rural. Esta situación se modificó hacia 1905, cuando se produjo un notable incremento del arribo de europeos a estas latitudes, que se extendió hasta los inicios de la Primera Guerra Mundial.

El aumento de la superficie cultivada estimuló el desplazamiento de nativos e inmigrantes desde las grandes ciudades, especialmente en

5. Cédulas de población del Segundo Censo Nacional, 1895. Partido de Pergamino, Provincia de Buenos Aires (AGN), Legajos 801, 802 y 803. 
las coyunturas de fuerte desocupación urbana (Alsina, 1905: 291-292). La necesidad de conseguir dinero para sobrevivir llevó a que miles de trabajadores se movilizaran hacia los campos entre diciembre y mayo, tal como lo evidencia el caso de los vendedores ambulantes (que se calculaban en 12.000 para 1901), de los obreros de la construcción o de los mecánicos, donde unos 2.000 se ofrecian como maquinistas y foguistas. ${ }^{6}$ De este modo, confluían con torneros, costureras o zapateros que migraban a los campos empujados por la fluctuación propia de sus labores durante el periodo estival (Garcia Costa, 1990: 146-154).

Esta primera etapa de la expansión agrícola, a diferencia de lo que sucedería a mediados de la década de 1900, no estuvo caracterizada por el papel protagónico de obreros golondrina (aquellos que viajaban sólo por seis meses y luego retornaban al Viejo Mundo). En este sentido, desde diversas publicaciones se argumentaba que la mayoria de los inmigrantes que se desplazaban en tercera clase desde Europa venían por un periodo de tiempo más prolongado -alrededor de cinco años-, dado que no resultaba redituable en términos económicos regresar a los seis meses a su país de origen. ${ }^{7}$

También se desarrollaron migraciones urbano-rurales con destino a las cosechas dentro de los propios partidos de la provincia, como ocurría, por ejemplo, con los barraqueros de Bahía Blanca, los albañiles de Coronel Pringles o los empleados contratados para el tendido de las vias férreas en el sur bonaerense. Una vez que finalizaban esas tareas se trasladaban hacia los campos para transformarse en jornaleros agrícolas. ${ }^{8}$

Ante el progresivo crecimiento de la superficie sembrada, otra de las estrategias que alentaron diversos sectores de las clases dominantes para resolver el problema de la mano de obra para la cosecha fue estimular las migraciones internas de trabajadores desde otras regiones del país. ${ }^{9}$ Sin embargo, este tipo de iniciativas tuvieron escaso éxito cuando pretendieron movilizar a pobladores del norte argentino (Volkind, 2015). A los sujetos que realizaban este periplo por iniciativa propia, Bialet Massé los caracterizó como los "golondrina criollos". Se trataba de santiagueños, cordobeses y correntinos, algunos catamarqueños y riojanos y uno que otro tucumano que migraban a Santa Fe y Córdoba para la cosecha (1985: 150).

Otro afluente de mano de obra que fue cobrando alguna importancia

6. La Prensa, 30 de agosto de 1901; La Agricultura, 27 de noviembre de 1902.

7. La Prensa, 22 de septiembre de 1897; La Agricultura, 13 de noviembre de 1902. A lo largo del período bajo estudio se registró un ingreso promedio anual de 110.000 extranjeros a la Argentina (Vázquez-Presedo, 1971: 15).

8. La Prensa, 23 de agosto de 1901; La Vanguardia, 17 de agosto de 1901.

9. La Nación, 29 de noviembre de 1902. 
con el paso del tiempo era el de los denominados linyeras, individuos de vida errante que desempeñaban diversas labores agrarias munidos de su pequeño atado de ropa y algunos utensilios a cuestas (Nario, 1980: 8).

\section{Dinámica del mercado laboral agrícola}

Atendiendo a las características del funcionamiento del mercado de fuerza de trabajo agrícola, existían diversas formas y mecanismos para procurar ocupación en las distintas faenas.

En general, si se contrataban peones para la preparación del suelo, la siembra o el cuidado de los cultivos, éstos provenían de las zonas próximas, permanecian varios meses en la unidad productiva y existía un amplio conocimiento y mayor familiaridad con el patrón. Esta vida, según Bialet Massé (1985), "casi común” que llevaba con el chacarero, ese vínculo más estrecho, dificultaba las negociaciones salariales.

A la hora de la cosecha, confluían en las zonas rurales miles de personas con diversos orígenes, experiencias y anhelos. Los que se desplazaban desde las grandes ciudades del litoral podian inscribirse en una agencia privada de colocación, que tomaba a su cargo la tarea de conseguir conchabo a las personas que contrataban sus servicios. Estas empresas se valian para ello de distintos medios, como la publicación de avisos clasificados en los diarios. A cambio de estas prestaciones, las agencias cobraban a los obreros elevados porcentajes de sus salarios y en infinidad de casos ofrecían condiciones laborales que luego no se cumplian. ${ }^{10}$

La forma de contratación de los trabajadores más calificados, como maquinistas y foguistas, era diferente. En algunos casos ofrecian sus servicios a través de publicaciones en los periódicos o podian tener un trato preferencial en las agencias. ${ }^{11}$ Por el papel que cumplian en la trilla, era común que -al igual que en la actualidad-los dueños de las trilladoras los contrataran a partir de un cierto conocimiento previo. Los obreros que desarrollaban esta tarea podian llegar a entablar una relación más estrecha con el propietario de este medio de producción, quien depositaba en las manos del asalariado una costosa inversión.

Otros se trasladaban por cuenta propia hacia los partidos bonaerenses, se arrimaban al almacén, a la casa de acopio o al boliche y esperaban que algún patrón agrario los convocase. En general, estos obreros agrícolas transitorios solian tener muchas dificultades para sobrevivir durante el tiempo de espera -a veces prolongado- que debían transitar

10. La Nación, 7 de diciembre de 1895; La Nueva Provincia, 4 de marzo de 1904; La Vanguardia, 24 de octubre de 1903; La Protesta, 28 de septiembre de 1904.

11. La Nación, 6 de diciembre de 1897. 
entre el arribo a la estación y la ocupación efectiva en la chacra. Una vez finalizadas las tareas se desplazaban a otras zonas donde pudieran encontrar trabajo. Sin embargo, las transiciones entre una labor y otra no siempre resultaban armoniosas. La mayoría de los jornaleros tenía dificultades para conseguir ocupaciones sucesivas, a veces podian transcurrir días, semanas y hasta meses enteros desocupados. En esos períodos, los asalariados se consumían los restos de los jornales abonados y sufrian la apremiante necesidad de vender nuevamente su fuerza de trabajo en el campo o en la ciudad (Lallemant, 1974: 181). Al respecto, La Prensa informaba que en 1901 habia en la ciudad de Buenos Aires unos 20.000 obreros que sólo accedian a trabajos transitorios y otros 6.500 inmigrantes desocupados que sólo conseguian empleo en las cosechas. ${ }^{12}$ Así, miles de trabajadores que residian en las urbes obtenian lo principal de sus ingresos a partir de las labores que realizaban en el ámbito rural.

El Estado nacional también intervino con el objeto de garantizar la provisión de brazos para la cosecha. Sin embargo, las medidas que implementó tuvieron modestos resultados tanto en la atracción de los inmigrantes a nuestro país como en la distribución de los recién llegados en los diversos partidos del interior bonaerense. ${ }^{13}$

En la medida en que la expansión del área sembrada era más veloz que la disponibilidad de mano de obra, y si no se transitaban coyunturas de fuerte desocupación urbana, podían generarse desajustes temporales entre la oferta y la demanda de fuerza de trabajo. Así, a partir de 1895 comenzaron a reiterarse las quejas de los contratistas, grandes terratenientes y pequeña burguesía agraria sobre la falta de jornaleros para recolectar los granos, lo cual podía resultar más notorio con respecto a la juntada maicera. ${ }^{14}$ Sin embargo, la contracara de esta situación no se explica, en todos los casos, por la escasez real de trabajadores sino que la precariedad de los salarios, los engaños de las agencias de contratación y las condiciones de trabajo que se ofrecian limitaban -en ciertos momentos- el desplazamiento hacia las zonas rurales. Por otra parte, a esta situación se le sumaban las dificultades

12. La Prensa, 21 de noviembre de 1903; El Comercio, 23 de octubre de 1902; La Protesta, 31 de octubre de 1903; La Agricultura, 7 de abril de 1904; La Prensa, 21 de agosto de 1901.

13. Memorias del Departamento General de Inmigración, 1896, 1897, 1898, 1900; Alsina (1903: 23-26).

14. La Prensa, 1 de enero de 1904. En reiteradas oportunidades, estos reclamos tenían por objeto incrementar la oferta de fuerza de trabajo en alguna localidad determinada para así imponer menores jornales a los trabajadores que se habian movilizado y no tenían otras alternativas para sobrevivir. 
para resolver favorablemente en la justicia los conflictos que se suscitaban con sus patrones. ${ }^{15}$ Se evidencia, de este modo, que existía una problemática abierta, ineludible y paradójica: desocupación y falta de brazos simultáneamente.

En relación con este panorama, cabe remarcar que el desarrollo de un proceso de urbanización y proletarización en la región pampeana tuvo la particularidad de que, en lo fundamental, no se correspondió con el crecimiento de un polo industrial pujante y diversificado que absorbiera de manera sostenida y estable la fuerza de trabajo creciente alimentada año tras año por los flujos de la inmigración (Pianetto, 1984: 301).

En este sentido, la dinámica laboral en curso, signada por la transitoriedad de las labores y el permanente desplazamiento entre los ámbitos rural y urbano, resultaba consistente con la estructura productiva que se iba configurando en el núcleo pampeano de la Argentina moderna. Así, entre las actividades que demandaban mayor proporción de trabajadores estaban aquellas vinculadas con el comercio, la construcción y la cosecha de granos, lo cual contribuyó a consolidar una "infantería ligera del capital" que rotaba entre diversas labores. ${ }^{16}$ Esta presencia entrega uno de los rasgos distintivos de la estructura socioeconómica local, donde todavía no se configuraba un clásico "ejército de reserva" que presionara sobre el salario de los obreros ocupados, sino que la proporción mayoritaria de los proletarios vivia en la inestabilidad laboral.

\section{De las "luchas diarias" a los primeros conflictos}

Los trabajadores agrícolas, que mayoritariamente se desempeñaban en tareas transitorias, desarrollaban sus labores en condiciones muy precarias. El trabajo en la cosecha de maíz resultaba extenuante, sobre todo cuando las plantas tenían muchas malezas. No sólo se estropeaba la ropa sino que mujeres, hombres y niños estaban más expuestos a lastimarse. Muchas veces padecian infecciones en las manos que eran dificiles de curar por la ausencia de condiciones de higiene y de atención médica. Por esta razón, los juntadores solían exigir un sobreprecio por bolsa para compensar la lentitud de la tarea. Avanzada la temporada y con las primeras heladas de otoño, la labor se volvía más sacrificada. El rocío mojaba los pies y, en lotes con mucha gramilla, también se humedecía la ropa hasta la cintura. Las escarchas de las heladas en las chalas también producian cortes. Además, no faltaban los dolores

15. La Prensa, 6 de septiembre de 1904; La Vanguardia, 9 de abril de 1904; La Agricultura, 27 de junio de 1895 y 30 de abril de 1903.

16. Sobre el tema, ver Marx (1995: 563). Esta conceptualización fue retomada por Sartelli (1997). 
musculares y sobre todo el de cintura, ya que el cosechero se desplazaba todo el día con las piernas abiertas y a medida que pasaban las semanas las plantas de maíz comenzaban a volcarse y era necesario inclinar mucho el cuerpo para alcanzar las espigas (Buratovich, $\mathrm{s} / \mathrm{f}$ ).

Estos obreros pasaban de dos a tres meses en la misma chacra. Se alojaban en una especie de choza construida con palos unidos con alambres y cubiertas con la chala del maíz. La chala, a su vez, también era utilizada a modo de colchón, debido a que no existía ninguna protección contra el frío que arreciaba en los meses finales de la tarea (Miatello, 1915).

Para los juntadores de maíz la jornada se extendía de sol a sol (en realidad de estrella a estrella), y sólo se interrumpía para comer. El almuerzo y la cena consistian en pucheros muy sencillos mientras que para el desayuno y merienda se consumía mate cocido y galleta. ${ }^{17} \mathrm{En}$ muchas oportunidades se acordaba con el peón el pago del salario más la comida. Si el alimento no era provisto por el chacarero, la familia cosechera debía cocinar en un fogón improvisado. La remuneración para estos trabajadores se fijaba a destajo, o sea en función de la cantidad de bolsas recolectadas por día. De este modo, los contratadores pretendian transferir al juntador la responsabilidad sobre los montos de sus jornales. ${ }^{18}$

Los trabajos requeridos en la producción agrícola triguera, especialmente en la cosecha, también resultaban extremadamente duros y pesados. Tanto el corte y trilla como la realización de las parvas, el acarreo y la estiba implicaban grandes esfuerzos y riesgos que se prolongaban en jornadas agotadoras (Sartelli, 2000; Ascolani, 2009). A esto se sumaba la impericia de muchos dueños de trilladoras que -por desconocer el modo adecuado de su funcionamiento- exponian al peón a un ritmo feroz y a un gran peligro físico por la posible explosión del motor a vapor y el incendio de la trilladora, que en general traía aparejada la muerte de varios trabajadores. ${ }^{19}$

Las tareas en la zona del trigo, en los aspectos referidos a duración y alimentación, no diferían de las experimentadas por los juntadores de maíz, salvo en lo que respecta a las viviendas. Para los trabajadores ocupados en la cosecha triguera ni siquiera existía la posibilidad de construir una choza de chala, ya que solian permanecer menos tiempo en cada chacra, no contaban con la materia prima y, por lo tanto, debian dormir a la intemperie.

17. La Protesta, 28 de septiembre de 1904; La Vanguardia, 23 de enero y 13 de febrero de 1904.

18. La Prensa, 6 de septiembre de 1904.

19. La Prensa, 18 de enero y 4 de febrero de 1904; La Nación, 15 de noviembre de 1905. 
En torno a la problemática salarial, la ausencia de estadísticas oficiales, referencias en los periódicos obreros e investigaciones de organismos públicos o privados dificultan la posibilidad de elaborar series completas y conocer con precisión los montos y la evolución de los mismos. Sin embargo, puede advertirse que el ingreso percibido por los peones contratados para la preparación del suelo, siembra y cuidado de los cultivos solía abonarse por mes (debido a que eran tareas que se prolongaban por varias semanas) y era sensiblemente menor a la suma de los jornales recibidos por los peones de cosecha. Para esta última tarea existía todo un escalafón salarial vinculado al tipo de labores desempeñadas por los obreros. Los mejores pagos eran los maquinistas y foguistas de las trilladoras: además de su remuneración mensual recibian un porcentaje cada 100 kilogramos de trigo que se procesaba. En cambio, un peón de horquilla o de parva percibía un monto muy inferior y se le abonaba por jornal. ${ }^{20}$

La aludida segmentación del mercado de fuerza de trabajo en el terreno salarial no sólo se explica por las diferentes calificaciones demandadas. También incidian la ubicación geográfica de la chacra y el tipo de cultivo. Al respecto, tenía mucha relevancia la densidad de población en el área, la cercanía a importantes centros urbanos, el tamaño de las explotaciones (y por lo tanto el requerimiento simultáneo de peones) y la importancia de la producción cerealera en ese partido. En ese sentido, el hecho de que en el norte bonaerense se pagaran montos más elevados a los juntadores de maíz, mientras en el sur de la provincia se ofrecieran mejores jornales a los peones de trilla, respondía justamente a las características productivas de cada región.

La desigualdad de género a la hora de fijar las remuneraciones fue otro de los factores que se evidencian desde los inicios del capitalismo en Argentina. Mientras que los varones con manutención cobraban $\$ 18,17$ $\mathrm{m} / \mathrm{n}$, las mujeres sólo percibían $\$ 9,75 .{ }^{21} \mathrm{Al}$ respecto, en un informe oficial de 1898 se afirmaba que un boyero (joven que cuidaba de los animales) recibía $\$ 30$ pesos mensuales mientras que una cocinera en una chacra mediana o grande cobraba $\$ 20$ por mes (Seguí, 1898: 51).

Con respecto a la evolución de los montos salariales podemos identificar dos momentos. En un principio, a lo largo de la década de 1880, los demandantes de fuerza de trabajo rural tuvieron que elevar los jornales que ofrecian para estimular los desplazamientos hacia los campos, ya que la construcción de ferrocarriles, las obras públicas y privadas y la posibilidad que aún existía -en cierto grado y medida- para acceder a una parcela de tierra impactaban sobre la disponibilidad de obreros

20. Anuario Estadístico del Ministerio de Agricultura de la Nación (1901).

21. Censo Agricolo-pecuario de la provincia de Buenos Aires (1888: 94). 
agrícolas para las cosechas. Esta afirmación, sin embargo, puede ser matizada en función de los elementos de juicio que entrega el experimentado ingeniero agrícola Florencio Molina sobre los ingresos de los jornaleros santafesinos. Molina argumentaba que, en aquel período, el tiempo de trabajo necesario para la reproducción de la fuerza de trabajo era de cuatro horas y media mientras que esos trabajadores cumplian jornadas de 12 horas o más. Los años "normales" eran aquellos en donde los salarios eran bajos, lo contrario era una excepción y no la regla (Blanc Bloquel et al., 1987: 287). Esto evidencia una elevada tasa de explotación por parte de los múltiples empleadores temporarios, situación que resulta opacada por aquellos que resaltan la supuesta existencia de jornales elevados en la época.

Luego, hacia 1890, los salarios rurales perderian su "atractivo" por el impacto de la crisis y sus repercusiones. Diversos indicios señalan que, durante la década de 1890, en Buenos Aires, los jornales medios de las diversas ocupaciones no acompañaron los incrementos en los precios de bienes y servicios (Poy, 2015: 39 y 77-86). Al respecto, un periódico insospechado de obrerismo como el Review of the River Plate afirmaba que para 1895 el salario de un obrero rural era casi un 50\% inferior comparado con la década anterior (Girbal de Blacha, 1982: 170). Para la cosecha de 1898-1899, un funcionario del Ministerio de Agricultura reconocía una situación similar (Lahitte, 1908: 43-44).

Así, hacia fines del siglo XIX, un conductor de segadora-atadora podía cobrar un jornal de $\$ 2,50$, al igual que un horquillero de trilladora o un bolsero. En la juntada de maíz cada bolsa completa de 80 kilos se pagaba alrededor de $\$ 0,25$ a $\$ 0,30$ centavos mientras que en la ciudad de Buenos Aires un peón albañil recibía $\$ 2,20$ por día y un oficial $\$ 3,50$ (Seguí, 1898: 52 y 55; García Costa, 1990). En los inicios del nuevo siglo la situación se agravó producto del incremento de la desocupación urbana y de la mayor disponibilidad de brazos para las cosechas, que impactó nuevamente en el descenso de los salarios rurales.

Si bien estas cifras deben ser consideradas con muchos recaudos, indican que los ingresos percibidos por la gran mayoría de los peones rurales contratados transitoriamente sólo superaban a los de los trabajadores urbanos no especializados. Aunque si se comparan las remuneraciones por hora, el resultado se invierte, en detrimento de los obreros agrícolas. En las ciudades la jornada laboral rondaba las 12 horas mientras que en la cosecha podia alcanzar las 16 horas, "de estrella a estrella".

A su vez, el monto efectivo recibido en mano una vez concluida la tarea estaba mediado y condicionado por diversos procedimientos puestos en práctica por los dueños de trilladoras y almaceneros de ramos generales -a veces personificados en el mismo sujeto- mediante los cuales reta- 
ceaban los jornales. ${ }^{22}$ A la hora de calcular el salario que debía recibir cada trabajador, se le realizaban los descuentos correspondientes a los objetos consumidos durante las semanas que duraban las labores y que eran provistos por el dueño de la máquina: "alpargatas, tabaco, vino, calzoncillos, comida o bien adelantos en efectivo". Esto le permitía al empresario (que monopolizaba el abastecimiento de bienes para sus obreros) embolsar mayores ganancias debido a los elevados precios a los que vendia los bienes. Los trabajadores protestaron contra estas medidas y en los pliegos de reivindicaciones incluyeron reclamos que iban en ese sentido.

A lo largo de estas décadas se fueron acumulando el malestar, los reclamos y las tensiones, al tiempo que se perfilaban con mayor nitidez las particularidades de esa fracción de la clase obrera argentina. La conformación de este proletariado agrícola estuvo atravesada por múltiples factores que incidieron en el plano objetivo y subjetivo. Por un lado, resultó de la confluencia de diferentes sectores sociales: peones y campesinos expropiados del acceso a los medios de producción para garantizar su subsistencia, pequeños artesanos, cuentapropistas. Por otro, requirió de la amalgama de sujetos que provenían de diversas latitudes y portaban disimiles experiencias culturales: migrantes internos, obreros urbanos, jornaleros y campesinos inmigrantes que, en muchos casos, se proletarizaron al cruzar el Atlántico. A su vez, la dispersión espacial, la baja concentración de trabajadores por unidad productiva, la estacionalidad de las labores y la heterogeneidad de los empleadores que los contrataban también generaron mayores dificultades para reconocer y reconocerse (Villulla, 2015: 30).

Las tensiones que recorrian los vínculos laborales en las zonas rurales se evidenciaron fundamentalmente a través de conflictos cotidianos, informales, aislados y acotados, que se manifestaron incluso en el ámbito legal (Palacio, 2004: 161-162) ${ }^{23}$ Así, las diversas formas -latentes y manifiestas- en que se canalizó la protesta obrera no se explican sólo por condiciones coyunturales adversas: "abundancia" de brazos, malas cosechas o crisis externa, sino que "más bien pueden definirse por la presencia de cierto tipo de conciencia politica acerca de dichas situaciones o antagonismos de parte de los trabajadores. Dicha subjetividad se fue cocinando con los ingredientes que le proporcionaban una experiencia singular, es decir, en determinado país, en cierta producción y proceso de trabajo, y en cierto estado de ideas en el seno de la sociedad y la clase de trabajadores que formaban parte" (Villulla, 2015: 31).

22. La Protesta, 12 de octubre de 1904.

23. Sobre el despliegue de otras formas de resistencia menos perceptibles consultar Scott (2000). 
Esta multiplicidad de elementos maduró en los primeros años del siglo XX. En una coyuntura caracterizada por la caída de los salarios reales, el incremento de la inmigración, el aumento de la desocupación urbana y el crecimiento de la superficie cultivada, se produjeron las primeras protestas de obreros agrícolas reflejadas por la prensa del periodo. ${ }^{24}$

En este proceso jugaron un destacado papel inmigrantes y criollos anarquistas y socialistas que buscaron agrupar y orientar politicamente a los asalariados rurales y a los pequeños y medianos agricultores. Los individuos arribados desde Europa contaban con un bagaje y una experiencia previa que tuvo mucha incidencia en la formación de los gremios rurales. Así, para 1901, se elaboraron los primeros pliegos de reivindicaciones mediante los cuales se reclamaban mayores salarios y mejores condiciones de trabajo para los operadores de las trilladoras. También, al calor de la extensión de los conflictos, se fundaron diversos centros y sindicatos que agrupaban a los obreros rurales del norte de la provincia de Buenos Aires. ${ }^{25}$

En este contexto, a instancias del Partido Socialista, se reunió en agosto de 1902 el Primer Congreso de obreros agrícolas, al que concurrieron 12 organizaciones de 10 localidades bonaerenses y santafesinas. ${ }^{26}$ Se acordaron allí varios reclamos, decidiéndose la conformación de la Federación Regional de los Centros Obreros del Norte y de la Costa de la Provincia de Buenos Aires y del Sur de Santa Fe. Si bien la vida de esta Federación fue efimera, su creación señaló el progreso de una nueva realidad que cobraba fuerza en la pampa a partir del peso creciente de los asalariados en las labores agrícolas.

Ilustrando esta tendencia, hacia 1904 se produjeron nuevos conflictos de obreros rurales, los cuales tendieron a desarrollarse en los periodos de cosecha, momento en el cual se concentraba el mayor número de asalariados y existían mejores condiciones para negociar. ${ }^{27}$ Sin embargo, estas protestas no podían extenderse demasiado debido a que el lapso de tiempo que había para recolectar los granos era relativamente breve. Así de breve también solía ser la vida de los sindicatos que se conformaban para unificar los reclamos de los braceros y obreros de trilladoras que se desempeñaban en la campaña entre los meses de diciembre y mayo (Ansaldi, 1993). ${ }^{28}$ Esta dificultad tenía como contracara la recurrente movilidad entre el campo y la ciudad que le permitía a los trabajadores

24. La Vanguardia, 22 de febrero de 1902; La Nueva Provincia, 4 de abril de 1903.

25. La Vanguardia, 7 de diciembre de 1901.

26. La Vanguardia, 13 de septiembre de 1902.

27. La Protesta, 24 de diciembre de 1904; Bialet Massé (1985: 689).

28. La Vanguardia, 9 de enero de 1904. 
entrar en contacto con las corrientes, los dirigentes y los sindicatos que se organizaban en el medio urbano y que tanta influencia tuvieron en el ámbito rural, particularmente el anarquismo que se amalgamó y sintetizó con la experiencia y el sustrato de esos peones rurales criollos.

\section{Conclusión}

A lo largo del período analizado, Argentina se transformó en un país dependiente y capitalista. La consolidación de esta nueva formación económico-social presentó un derrotero particular, sinuoso y zigzagueante, determinado por el entrelazamiento y la coincidencia de intereses entre los grupos oligárquicos locales (grandes terratenientes y comerciantes) y el capital extranjero y por la centralidad que tuvo la producción agropecuaria para exportación.

Este desarrollo se evidenció en el marcado crecimiento del número de asalariados rurales que atendieron las distintas tareas asociadas a una agricultura cerealera que se desplegaba a ritmos inusitados. Dichas tareas estacionales, articuladas con la demanda de obreros para las obras públicas, la construcción, el tendido de vías férreas o los trabajos portuarios, tendieron a generalizar una pauta de trabajo transitoria que integraba los ámbitos rurales y urbanos a través de los desplazamientos interregionales e intrarregionales. Esta dinámica laboral urbano-rural se fue expandiendo y acentuando entre una elevada proporción de la población económicamente activa, dado que la demanda de fuerza de trabajo industrial, de puestos fijos, no se hallaba suficientemente extendida. De este modo, la tendencia a la salarización de buena parte de la fuerza de trabajo se contrarrestaba parcialmente, o en todo caso hallaba una de sus mayores especificidades, en el hecho de que sólo durante unos meses al año los trabajadores tenían medianamente garantizada la venta de su peculiar mercancía. A pesar de esta situación, esta fracción del proletariado argentino se fue consolidando como producto de la amalgama de diversos ingredientes que le otorgaron una fisonomía particular y reconocible a pesar de la diversidad de experiencias, procedencias, costumbres, conocimientos y anhelos.

Estos peones agrícolas pampeanos desarrollaron sus labores bajo la inexistencia de leyes protectoras, durante jornadas interminables, en condiciones insalubres, recibiendo pésima alimentación y alojándose a la intemperie. Los salarios recibidos podian resultar tentadores para aquellos que desempeñaban tareas temporarias en las ciudades o en los pueblos y zonas rurales cercanas, pero el trabajo de estrella a estrella, la venta de mercancias a un costo muy elevado y las posibles deducciones a sus jornales a las que estaban expuestos, le quitaban parte de su atractivo. A su vez, fueron víctimas de engaños y estafas, no sólo 
por parte de los almaceneros de ramos generales, sino también por los titulares de las grandes explotaciones, las agencias de contratación y los empresarios de trilla, que se valieron de un sinnúmero de estrategias para garantizarse la explotación de la mano de obra necesaria al menor costo posible. Por lo tanto, habría que relativizar la idea, extendida entre algunos protagonistas de la época y en interpretaciones historiográficas posteriores, de que los salarios rurales eran elevados, expresión de dudosa validez teórica. Estas reconstrucciones historiográficas, en línea con una visión apologética de la etapa agroexportadora, presuponen la existencia de un crecimiento económico excepcional que habría permitido el "derrame" de la riqueza sobre el conjunto de la sociedad. Bordean, así, una lectura fisiocrática que asocia unilateralmente la riqueza nacional a la "productividad natural" y a las "ventajas comparativas" derivadas de la fertilidad del suelo argentino. De este modo, pretenden difuminar la relación social de explotación de la cual emanaba dicha riqueza.

Para contrarrestar las condiciones laborales y salariales, los trabajadores buscaron distintos canales de expresión: el reclamo particular, la rotura de una máquina o una presentación judicial. Entrado el siglo $\mathrm{XX}$, iniciaron un proceso de organización que derivó en la conformación de gremios y sindicatos, mayoritariamente orientados por socialistas y anarquistas. En este derrotero fueron conformando un sustrato común y reconocible que se evidenció a través de los diversos conflictos que protagonizaron en estos años.

\section{Referencias}

Adelman, Jeremy (1989), "Una cosecha esquiva. Los socialistas y el campo antes de la primera guerra mundial", en Anuario del IEHS, n ${ }^{\circ} 4$.

Alsina, Juan (1903), Población, tierras y producción, Buenos Aires.

- (1905), El obrero de la República Argentina, Buenos Aires.

Ansaldi, Waldo (comp.) (1993), Conflictos obreros rurales pampeanos (19001937), Buenos Aires: CEAL.

Ascolani, Adrián (1993), "Labores agrarias y sindicalismo en las villas y ciudades del interior santafesino (1900-1928)" en Adrián Ascolani (comp.), Historia del sur santafesino, Rosario: Platino.

- (1998), "Hacia la formación de un mercado de trabajo rural "nacional". Las migraciones laborales en la región cerealera (1890-1930)", en Res Gesta, ${ }^{\circ} 36$.

- (2009), El sindicalismo rural en la Argentina, Buenos Aires: Edunqui.

Azcuy Ameghino, Eduardo (2011), Una historia casi agraria. Hipótesis y problemas para una agenda de investigación sobre los origenes y desarrollo del capitalismo en Argentina, Buenos Aires: PIEA.

Beccaria, Luis (2006), "El mercado de trabajo argentino en el largo plazo: 
los años de la economía agro-exportadora”, Serie Estudios y Perspectivas, $\mathrm{n}^{\circ} 33$.

Bialet Massé, Juan (1985), Informe sobre el estado de la clase obrera, Buenos Aires: Hyspamérica.

Blanc Bloquel, Adriana, Marta Bonaudo, Elida Sonzogni y Carlos Yensina (1987), "Conformación del mercado de trabajo en la provincia de Santa Fe (1870-1900). Algunas aproximaciones", Anuario. Escuela de Historia UNR, pp. 271-316.

Buratovich, Tadeo (s/f), "La Juntada de maíz", Trabajos, publicaciones y notas de asesoramiento. Asociación de Museo de la Provincia de Santa $\mathrm{Fe}, \mathrm{http}: / /$ museosdesantafe.com.ar/descargas/35_texto8.pdf

Cilley Vernet, José (1896), Los cereales y oleaginosas trillados en la provincia de Buenos Aires en la cosecha de 1895-1896, La Plata.

Cortés Conde, Roberto (1979), El progreso argentino, 1880-1914, Buenos Aires: Sudamericana.

Diaz Alejandro, Carlos (1975), Ensayos sobre la historia económica argentina, Buenos Aires: Amorrortu.

Gallo, Ezequiel (1984), La pampa gringa, Buenos Aires: Sudamericana.

García Costa, Victor (1990), Adrián Patroni y "Los trabajadores en la Argentina", Buenos Aires: CEAL.

Girbal de Blacha, Noemí (1982), Historia de la agricultura argentina a fines del siglo XIX (1890-1900), Buenos Aires: Fundación para la educación, la ciencia y la cultura.

Lahitte, Emilio (1905), "Puertos, transportes y jornales", en Boletín del Ministerio de Agricultura, Buenos Aires.

- (1908), Informes y estudios de la División de Estadistica y Economía Rural, Buenos Aires.

Lallemant, German Avé (1974), La clase obrera y el nacimiento del marxismo en la Argentina, Buenos Aires: Anteo.

Martinez Dougnac, Gabriela (2010), "Viejas leyes aggiornadas y nueva legislación: reflexiones en torno al carácter y papel de algunos instrumentos de legislación agraria durante el primer peronismo", en Documentos del CIEA, $\mathrm{n}^{\circ} 5$.

Marx, Karl (1995), El capital. México: Fondo de Cultura Económica.

Miatello, Hugo (1904), Investigación agricola en la provincia de Santa Fe, Buenos Aires: Compañía Sudamericana de Billetes.

Miatello, Hugo (1915), El hogar agrícola, Buenos Aires.

Míguez, Eduardo (1993), "La frontera de Buenos Aires en el siglo XIX: población y mercado de trabajo", en Raúl Mandrini y Andrea Reguera, Huellas en la tierra, Tandil: IEHS.

Nario, Hugo (1980), "Los crotos", Todo es Historia, n 158.

Palacio, Juan Manuel (2004), La paz del trigo, Buenos Aires: Edhasa.

Panettieri, José (1988), El paro forzoso en la Argentina agroexportadora, Buenos Aires: CEAL. 
Pianetto, Ofelia (1984), "Mercado de trabajo y acción sindical en la argentina, 1890-1922”, Desarrollo Económico, nº 94.

Poy, Lucas (2015), Los origenes de la clase obrera argentina. Huelgas, sociedades de resistencia y militancia politica en Buenos Aires, 1888-1896, Buenos Aires: Imago Mundi.

Raña, Eduardo (1904), Investigación agrícola en la provincia de Entre Rios, Buenos Aires: Imprenta de M. Biedma e Hijo.

Sábato, Hilda (1989), Capitalismo y ganadería en Buenos Aires, Buenos Aires. Sudamericana.

- y Romero, Luis Alberto (1992), Los trabajadores de Buenos Aires. La experiencia del mercado: 1850-1880, Buenos Aires: Sudamericana.

Sansoni, Mariela (1990), "Mercado de trabajo agrícola y el paro estacional en el agro pampeano (1890-1920)" en Mercado de Trabajo y paro forzoso. Desde los comienzos de la Argentina moderna hasta la crisis de los años 30, UNLP.

Sartelli, Eduardo (1993), "Sindicatos obreros-rurales en la región pampeana, 1900-1922”, en Ansaldi, Waldo (comp.), Conflictos obreros rurales pampeanos (1900-1937). Buenos Aires: CEAL.

- (1997), "Ríos de oro y gigantes de acero: tecnología y clases sociales en la región pampeana (1870-1940)" en Razón y Revolución, $\mathrm{n}^{\circ} 3$.

- (2000), "Procesos de trabajo y desarrollo capitalista en la agricultura. La región pampeana, 1870-1940" en Razón y Revolución, $\mathrm{n}^{\circ} 6$.

- (2005), "Hombres y mujeres "cuyos nombres ignorase". El trabajo rural y el mito de la Pampa pródiga, 1880-1930" en Razón y Revolución, $\mathrm{n}^{\circ} 14$.

Scout, James (2000), Los dominados y el arte de la resistencia. México: ERA.

Segui, Francisco (1898), Investigación Parlamentaria sobre agricultura, ganadería, industrias derivadas y colonización. Provincia de Buenos Aires, Buenos Aires: Taller Tipográfico de la Penitenciaría Nacional.

Vazquez Presedo, Vicente (1971), Estadisticas Históricas Argentina, 18751914, Buenos Aires: Ediciones Macchi.

Villulla, Juan Manuel (2015), Las cosechas son ajenas. Historia de los trabajadores rurales detrás del agronegocio, Buenos Aires: Cienflores.

Volkind, Pablo (2015), "Un incierto y sinuoso camino: la formación del mercado de fuerza de trabajo en la agricultura bonaerense entre fines del siglo XIX y el inicio de la Primera Guerra Mundial", Revista Interdisciplinaria de Estudios Agrarios, $\mathrm{n}^{\circ} 43$. 